\title{
A Mechatronics Vision for Smart Wheelchairs
}

\author{
Yoshiyuki Noda*, Akira Kawaguchi** and Kazuhiko Terashima* \\ ${ }^{*}$ Toyohashi University of Technology \\ Japan \\ ${ }^{*}$ City College of New York \\ U.S.A.
}

\section{Introduction}

People are living longer and surviving better. The size of the population of potentially limited by age or disability is increasing at a dramatic rate, and it is no longer an insignificant or silent part of the society. According to a report (United Nation, 2007) published by the Department of Economic and Social Affairs, Population Division, of the United Nations, by the year 2025 aged people, or those of 60 years old or over, will comprise $15 \%$ of the world's population, and by the year 2050 this figure will reach $22 \%$ compared with $11 \%$ in 2007 , or nearly a third of the population in developed countries is projected to be in that age group. Moreover, a fact sheet published by the International Day of Disabled Persons (ILO, 2007) reports that around $10 \%$ of the world's population today is comprised of disabled people. This means that by the year 2025 around $1 / 5$ of the world's total population will need economic and social benefits as well as some kind of artificial perambulatory assistance in their daily lives.

The U.S. and Japan are facing aging problems. Projections based on the U.S. Census Bureau estimates indicate that the number of persons ages 65 and over will grow to almost 40 million by the year 2010 (Jones and Sanford, 1996). More than 4 million people in the United States are over the age of 85 and about 60,000 topped age 100. By 2020, the Census Bureau further estimates that 7 million to 8 million people will be over age 85 and 214,000 will be over age 100. Japan has a very serious challenge of rapid pace of aging. Most experts predict more than 27 percent of the population to be age 65 or more by 2017, and this increase will continue to reach $35.7 \%$ in 2050 (Oe, 2006). It took only 24 years in Japan for the elderly population to grow from 7 percent to 14 percent. The speed of aging is the world's fastest and Japan's aging level will be the highest in 2010. Japanese society is in the midst of this rapid change, and community accessibility and social welfare have become major policy issues.

As life expectancy rises and modern medical treatment improves survival, there is a growing interest in building more advanced support structures for society. In particular, a desire for the enhanced quality of life with wheelchair is a steadily growing phenomenon (First Research Inc., 2007), and is generating a strong demand for a lesser restrictive environment of barrier-free accesses, safer and better route selections, more transportation alternatives, and so on. The motivation for this chapter is to pose a fundamental question on 
the handling of these challenging problems. We shall look into a missing part of today's transportation systems in the context of wheelchair's mobility, with our aims to explore the establishment of support systems to respond these foreseeable changes in demographics. The public acknowledgment of people with disabilities and progress toward enhanced cares have developed in the last few decades along three parallel tracks of activities (Longmore and Umansky, 2001) - these are legislation spurred by the disability rights movement, barrier-free design to universal design movement, and advances in rehabilitation and assistive technology. Nevertheless, there still remains an area that ought to be examined more seriously from an economic standpoint. We call this area a mechatronics support service, which lies as a support technology centered on mechanics, electronics, and computing.

The mechatronics support in our vision is meant to emphasize a synergistic integration of the latest techniques in cross-disciplinary fields. It is an approach for a pragmatic establishment of the society-driven transportation structure for the vulnerable people (Kawaguchi, et al., 2008). The so-called assistive technology (Cook, 2002) in computerized aid, care, and support for the people in mobile wheelchairs is evolving rapidly. It is in a technical branch that indeed spans autonomous process control, intelligent engineering systems, and information management. While transformative as well as establishing stronger through world-wide collaboration, there exists no widely accepted practice or reference model that leads to the integration of these assistive technical elements into mass transportation systems today. This chapter studies several key issues in bringing into an infrastructure and surrounding information system that hosts micro and macro control for the smooth and safe navigation of mobile wheelchairs in the public transportation environment. More specifically, we propose a high-level architecture that facilitates terrain surveillance and intelligence gathering through laser sensor implanted in the wheelchair, for the purpose to identify the obstacles and unusual patters of movement to predict accidents. This can be achieved by a number of sensors to map the environment into an appropriate perception-action model, which is then employed for planning and controlling the locomotion of the wheelchair. Information technology plays key roles for assisting the understanding of travel route and physical situations at the movement of wheelchair. All the technical elements highlighted in this paper are our on-going collaborative efforts between the U.S. and Japan.

The contributions of this chapter are threefold: first, a short survey on the accessibility issues related to today's mobile wheelchairs and various effort for the enhancement of public accessibility in transportation perspective is given to set the orientation of this research; second, foundations for and high-level specifications for micro and macro-control architecture developed based on the proposed mechatronics approach are explained; third, a product of a navigation guidance system using a haptic feedback joystick for an omnidirectional wheelchair is introduced as a micro-control support, and an example of a macrolevel information support system using New York City bus transit service is discussed. The widespread use of autonomous mobile wheelchairs has a socioeconomic impact. The significance of this research for the longer-term goals lies in its implications for adaptation of our intelligent support model into the future welfare activities. 


\section{Today's Mobile Wheelchairs in the U.S. and Japan}

The demand for wheelchairs and other mobility devices in the U.S. is projected to increase 5.0 percent per year through 2010 to over $\$ 3$ billion (Supplier Relations, 2007). This is partly due to the mobility impairing conditions accompanied by the aging of the baby boomer population in the U.S. (First Research Inc., 2007). The growth estimated will be similar for other devices designed primarily for disabled persons such as powered scooters and specialty elevators (Market Research, 2007). Advances in electronic controls, battery technologies, lightweight materials of construction and other areas are stimulating the growth in both the wheelchair- and non-wheelchair-related segments of the personal mobility devices industry.

\subsection{Popular mobile wheelchairs in the U.S. and Japan}

Electric wheelchairs, generally designed for both indoor and outdoor use, are prescribed for individuals who have difficulty using a manual chair due to arm, hand, shoulder or more general disabling conditions such as a lack of leg strength to propel a manual chair with their feet. Most electric wheelchairs consist of a seat and back, two small front wheels and two large rear wheels, a foot rest, and a joystick that allows directional movement such as driving forwards, backwards, and sideways, and turning round on the spot while moving (Yanco, 1998). Various parts often customized and added for the user's needs, such as the seat size, seat-to-floor height, footrests or leg rests, front wheel outriggers, adjustable backrests, and so on. Optional accessories are also available, such as anti-tip bars or wheels, tilt and/or recline features, adjustable backrests, safety belts, extra support for limbs or neck, mounts or carrying devices for crutches, walkers, drink holders, and clothing protectors.

Some of the leading manufacturers of mobile wheelchairs are AdaptaChair (U.K.), Balder Power Wheelchairs (U.S), Bromac Assistive Technology (U.S.), ConvaQuip (U.S.), Everest \& Jennings (U.S.), Euroflex (Sweden), Falcon Rehabilitation Products (U.S.), Giraldin (Italy), Invacare Products (U.S.), IBOT (U.S.), Levo (Switzerland). Magic Mobility Extreme (Australia), Meyra (Germany), OmegaTrac (U.S.), Otto Bock, Permobil (U.S.), Quickie (U.S.), Rascal (U.S.), Redman Power Chair (U.S.), RGK Wheelchairs (U.S.), VERTRAN (U.S.), Kawamura (Japan), Yamaha (Japan), Suzuki (Japan), Matsunaga (Japan), etc.

These manufactures classify electric wheelchairs into transportable, powerbase, and heavyduty types. Transportable type weights less than $100 \mathrm{lbs}$ and has a compact size suitable for confined spaces or narrow doorways. The lightweight frames easily fold or disassemble into manageable pieces making them the lightest and easiest to carry. Powerbase type provides a range of options for suspension, driving, seating and handling, and has a low center of gravity and a tight turning radius with large battery range, thus, making the ride smooth and stable for outdoor and indoor use, but does not fold or disassemble. Heavy-duty type is for outdoor use, equipped with rear, front and mid wheel drive options, and larger wheels. Larger motors and longer frames allow the increase of torque over other types, thus providing a smooth ride over rough terrain and up some inclines.

\subsection{Controlling electric wheelchairs}

The mobility of these chairs relies on electric motors, usually powered by 4 or $5 \mathrm{amp}$ deepcycle rechargeable batteries available in wet (or liquid electrolyte), gel (or pasty low- 
moisture electrolyte), or AGM (Absorbed Glass Mat) types. Batteries are usually on-board rechargeable through a standard wall outlet. The adjustment of the speed and direction of wheelchairs can be mostly made by operating a joystick on a controller (see Fig.1). More complex devices, such as chin controls and puff/suck scanners, can be customized for those with severe and/or multiple disabilities, e.g., spinal cord lesions and lack of hands or fingers. There are three standard ways of propelling electric wheelchairs (Yanco, 1998; Market Research, 2007): rear wheel drive is most common for electric wheelchair, which makes the wheelchair fast but has a comparatively poor turning capability, mid wheel drive has best turning capability but is not suitable for uneven surfaces, and front wheel drive gives a lower top speed than rear wheel drive chairs, but offers a good turning capacity. Recent expensive model has gyroscopic circuitry that enables the chair to rise on two wheels. Various powered functions such as tilt, recline, leg elevation, and seat elevation are also available in most equipments.

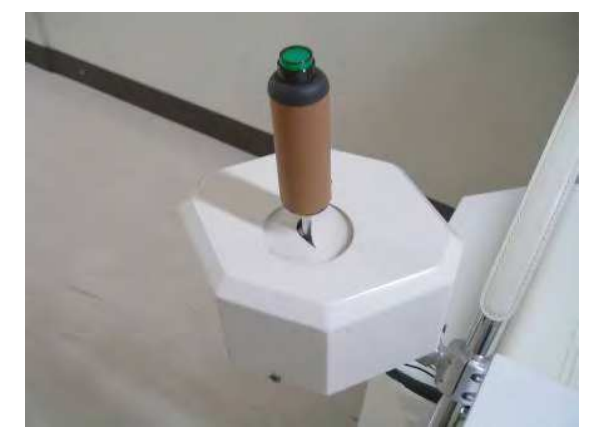

Fig. 1. Joystick

\subsection{Support and regulation structures in the U.S. and Japan}

Today's built environment shows a significant transformation that makes it more accessible to wheelchair users. This kind of transformation has been brought by the law and longstanding movement with aims of supporting people with disabilities to live as more

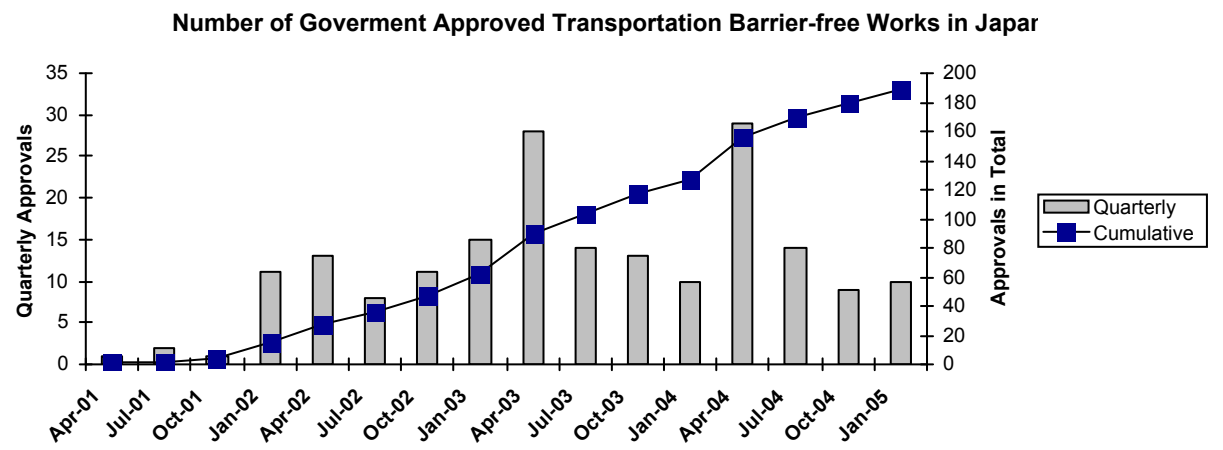

Fig. 2. Recently approved accessibility improvement works in Japan

(Source from Ministry of Land, Infrastructure and Transport, 2006) 
active participants in the society. Noticeable changes are visible in many cities and parts of the world, such as the installation of elevators, transit lifts, and wheelchair ramps in public areas. Especially in the advanced countries, such improvement is increasingly enforced for the access to public areas such as city streets and public buildings and restrooms, thus allowing people in wheelchairs and with other mobility impairments to use public sidewalks and public transit more easily and more safely (ILO, 2007). The demographic, legislative, economic, and social changes that brought us to this point are increasing the momentum that will propel us into a more modern transportation structure that enables maximum inclusion of all people.

In the U.S., the public law called the Americans with Disabilities Act of 1990 (ADA. (1990)) prohibits discrimination based on disability, in which disability is broadly defined as a physical or mental impairment that substantially limits a major life activity. In effect, all people regardless of disability are entitled to equal access to all parts of the society such as public transportation and buildings. The disability rights movement in the U.S. prevailed the nation during 1970s and grew into a significant force as a precursor of the ADA regulation to establish the civil-rights status for disable people. The ADA has uniform nationwide rules that ensure the accessibility regardless of local attitudes and governances. The Architectural and Transportation Barriers Compliance Board (Access Board) issued Accessibility Guidelines for accessible design in 1991, and these guidelines became the enforceable ADA Standards for Accessible Design. Today's most new construction for public use must be built to ADA standards of accessibility. Wheelchair users are now becoming free to access the environment without stairs, especially for more law-enforced places like education and employment.

Japan has been taking a number of legislative steps to address the challenges, chiefly led by the government, socially concerned architects, engineers, and advocates. In 1994, Japan implemented The Law for Promoting Easily Accessible and Useable Building for the Aged and the Disabled (so called Heart Building Law) to provide guidelines for accessibility to public facilities such as hospitals, theaters, and municipal buildings. Revised in 2002, the scope and size of buildings are expanded, and local governments such as cities, towns and villages are given full authorization to enforce stricter requirements and decide focus areas for improvement (see Fig. 2). The law is now mandatory if building is larger than 2000 square meters. Furthermore, The Law for Promoting Easily Accessible Public Transportation Infrastructure for the Aged and the Disabled (so called Barrier-Free Transportation Law) established in 2000 requires public transport to adhere to a series of accessibility regulations. These two laws are integrated into so-called New Barrier-Free Law in 2006. Japanese citizens strongly support the current systems.

\subsection{Universal design in public transportation}

Universal design is a design paradigm that aims to reduce the physical and attitudinal barriers between people with and without disabilities. This concept emerged from barrierfree design principles and assistive technology - the former provides a level of accessibility for people with disabilities, and the latter enhances the physical, sensory, and cognitive abilities of those people (Orpwood, 1990). The concept of universal design gives a broadspectrum of solutions that help everyone, not just people with disabilities, and it is now becoming one of the most important design elements that range in scale from product 
design to architecture and urban design, and from simple systems to complex information technologies (NCODH, 2005).

The forthcoming transportation facilities are therefore likely in compliance with the universal design principles. Especially in public transportation, universal design policy aims to create an environment that enables everyone to move freely and safely. Diverse parties responsible for public conveyance such as bus, rail, aircraft, and intercity or commuter rail transportation, must accomplish smooth and easier transfer at their connection points and flexible routing selection over those services. This must be done based on their cooperative efforts instead of competitive relationships (MLIT, 2006). As an example, the ADA requires new transit buses be accessible to people using wheelchairs (by lift or ramp) and have at least two spaces to secure wheelchairs in each bus. The construction of low floor trams and non-step buses is a trend and today's street furniture design incorporates better accessibility even for people with disabilities.

\subsection{Paratransit services}

Paratransit is another mode of passenger transportation that has been increasingly served for handicapped commuters and travelers, which in general does not follow fixed routes or schedules, but uses typically vans or mini-buses for the higher flexibility for picking up or discharging passengers on request. Most vehicles are specially equipped with wheelchair lifts or ramps to facilitate access, thus allowing people with disabilities to have jobs by providing transportation to and from their workplaces (Simon, 1997).

A sub-sector and private business are on the rise to meet the growing interest in the paratransit strategy, but the cost for serving low-density areas and dispersed trip patters does not balance with today's declining financial conditions, which may create an urgent need for public transit operators instead to maximize all available transportation resources. Veolia Transport and Laidlaw International, Inc. are two of the largest providers of contract paratransit services in North America (Veolia Transport is also successful in Europe and Australia). Paratransit in Japan is part of the health and welfare systems. Thus the service is small-in-scale from the transportation standpoint, while in Hong Kong, a territory-wide Rehabus transport network service is provided by the Hong Kong Society for Rehabilitation.

\section{Mechatronics Approach for Enhanced Mobility}

Imagine a great influx of people in wheelchairs having to navigate through crowded aisles and streets. Sidewalks can be harmful or even impassible by those wheelchairs. Many factors even including laws may need to be reconsidered for roadway traffic, parking space, and accident handling. As an example, since people with disabilities who use wheelchairs are considered pedestrians under many authorities in the U.S. and Japan, at serious traveling speeds the chairs can endanger other sidewalk users, raising a similar debate on whether bicyclists should be allowed to ride bicycles on sidewalk. Building more comprehensive support structures as well as better protections for wheelchair users becomes mandatory in the near future. This section looks into the so-called mechatronics approach (Mahalik, 2003) for coupling a wide range of hardware components and software functionalities using standard interfaces, which enables wheelchairs to possess a degree of intelligence, ultimately to predict and avoid risky situations and navigate safely in congested areas and confined spaces. Capabilities of sensor-based feature detection and 


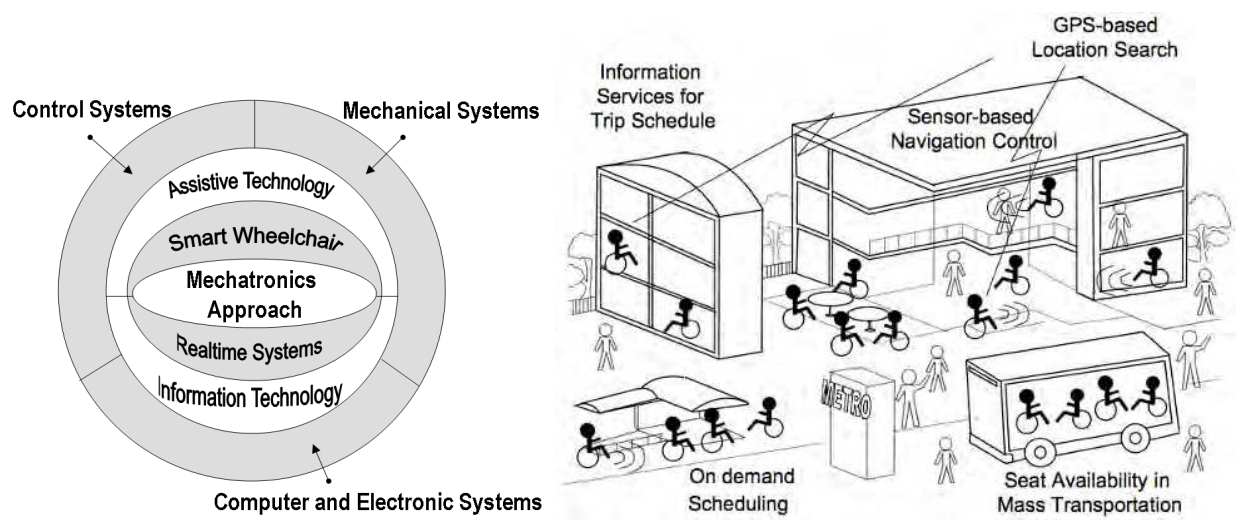

Fig. 3. Mechatronics approach for mobile wheelchair support in transportation

computerized navigation assistance available today make this kind of electromechanical cares possible.

\subsection{Mechatronics approach}

Mechatronics shares the common goal of systems thinking towards a synergistic combination of precision mechanical engineering, electronic control, and information processing. This is to achieve an optimal balance between basic mechanical structure and its overall control. In the scope of wheelchair's mobility enhancement, machatronics approach aims to an effective integration of assistive technology and information technology (Kawaguchi et al., 2008), by way of embedding real-time microprocessor control (microlevel control) for understanding the surrounding condition through laser sensor and applying on-demand communications to information points (macro-level control) for wheelchair to follow directions by extrapolating and comparing to the route pre-selected by the user (see Fig. 3).

The outcome of this effort can be broadly framed as an electrically powered wheelchair that is equipped with an intelligent assistance system being capable of (1) recognizing anticipatorily the user's intent according to a given situation and (2) guiding a trip to destination safely and reliably to a high degree based on given instructions such as travel routes and transportation methods. Notice that no single form of implementation exists due to the need of adaptations to various human factors such as severely handicapped or elderly people with heavily reduced physical and/or mental abilities, weakened perception, etc. For these cases, special control devices (e.g. sip-puff-device) with restricted command sets need to be developed.

Notice also the importance of community support in the development and deployment of the product. The mechatronics approach is a practice including a wide range of activities spanning design, instrumentation, computer integration, process and device control, and manufacturing. The successful implementation mandates not only interdisciplinary effort across the industrial and academic research spectrum, but also participation and cooperation of wheelchair users, transportation companies, disability advocates, and voluntary experts in public. Overall, it is a continuous process in which users in all parties 
participate actively from the preliminary study stage to the post evaluation stage, so that the knowledge and experience obtained through their participation process can be applied to the next level of innovation. In this regard, the concept we propose shares the philosophy and benefits of universal design - mechatronics approach serves the dual role of bringing greater recognition to this important area of engineering.

\subsection{Assistive technology as micro control}

Assistive technology (Cook, 2002) applies to devices for personal use to enhance the physical, sensory, and cognitive abilities of people with disabilities and to help them function more independently in environments oblivious to their needs. Its element closely related to realize mechatronics support is a smart wheelchair (Simpson, 2005) or an augmentative mobility aid that accepts a variety of different controls tailored to the rider's needs, and complements the rider's efforts by expanding and interpreting their limited control commands to provide safe transit (CALL Centre, 1994).

Fig. 4. Touch Panel

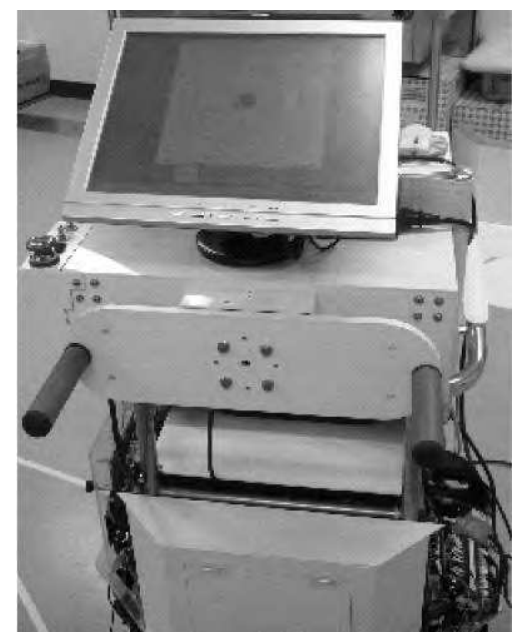

A smart wheelchair has a collection of sensors to work with several cognitive techniques similar to those developed in mobile robotics, but it is not necessarily acting autonomously because the aim is to complement and extend the user's abilities, not replace them. The typical interface consists of a conventional wheelchair joystick (or more complex input device) and a touch-sensitive display connected to a computer (see Fig. 4). Sensor techniques are chosen such as sonar, infrared radiation, and laser rangefinder, to understand the surrounding physical layout and to detect obstacles for navigation assistance and collision avoidance. The response is produced such that the system alerts and/or modifies user's choice of joystick drive command. Our recent attempt in this direction is discussed shortly. One drawback observed is that the majority of the smart wheelchairs that have been developed to date have been tightly integrated with the underlying power wheelchair, thereby requiring significant modifications to function properly (Simpson et al., 2004). The forthcoming research on the extension of smart wheelchairs, enhanced with path-planning, 
behavioral learning, and cognitive capabilities will have a significant impact on the outcome of the mechatronics implementation.

\subsection{Information technology as macro control}

Information technology is a key for providing flexible transportation services and increased choice for the users. In addition, useful information supplies psychological reassurance to vulnerable people to make them feel more safe and secure. A federal civil rights procurement law in the U.S. requires electronic and information technology to be accessible to people with disabilities. Flexible services are brought by a wide variety of innovative information services now in use increasingly in many countries. For instance, the presence of ubiquitous network technology that consists of IC tags, wireless tags, RFID tags, and other communication equipment such as portable information terminals makes it possible for elderly people and handicapped people to move freely and independently. The use of more economical PHS communication network generally available in Asian countries can afford precise tracking of the people in wheelchairs who move around dense urban areas like hospitals, libraries, and museums. GIS technology that allows conversion of geographical information into electronic form also facilitates the wide-scale integration of navigation assistance and tracking capability into various telecare information systems.

Up-to-date information of services such as availability, route guidance, cost, efficiency, and safety must be always available to improve the overall level of public transportation including railroad, bus, airline, and shipping. Traffic-aware routing based on portable GIS device is a new area in vehicle industries. At the same time, traditional internet-based software that can handle scheduling, dispatching and reservation, such as Ecolane DRT, PASS and NaviTrans, plays an important role to implement demand-responsive transportation schemes or flexible door-to-door paratransit service for wheelchair users.

Residents in metropolitan areas increasingly view the convenience of public transportation. They are becoming used to supply and retrieve information gathered for regional community. The accessibility improvement needs the exact same type of the cooperation of transportation companies and regional residents: transportation companies, private industries, public places, and any points of interest for residents such as restaurants, shopping centers, movie theaters, etc., must supply the accessibility information into a public database system, which in turn provides immediate retrieval for transportation and route selection, thereby giving great aids to realize macro control in wheelchair movement.

\section{Available Technical Elements}

A variety of electric wheelchairs with different options and special add-on features have been proposed to meet a wide range of needs in the drivability enhancement (Prassler, 2001; IEEE RAM, 2001). Amongst these capabilities, a driving mechanism called an omnidirectional movement has been realized and demonstrated at the Toyohashi University of Technology to satisfy the demand for better mobility in narrow space and confined area. In this section, we describe several enhancements made to this prototype toward the fulfillment of the proposed mechatronics-based integration. 


\subsection{Omni-directional mobile wheelchairs}

A wheelchair enhanced with omni-directional movement can have combination of forward, sideways, and rotational movement. Consequently, it yields better mobility and safety for the navigation of areas in the presence of many obstacles. The one designed and manufactured at the Toyohashi University of Technology (see Fig. 5) is based on the work of Wada and Asada (1999), in which each of the four balls to drive wheelchair is operated by an individual electric motor. The product shows the full capacity to move to any direction as well as rotate around while having abilities to change the angle between the beams holding these balls.
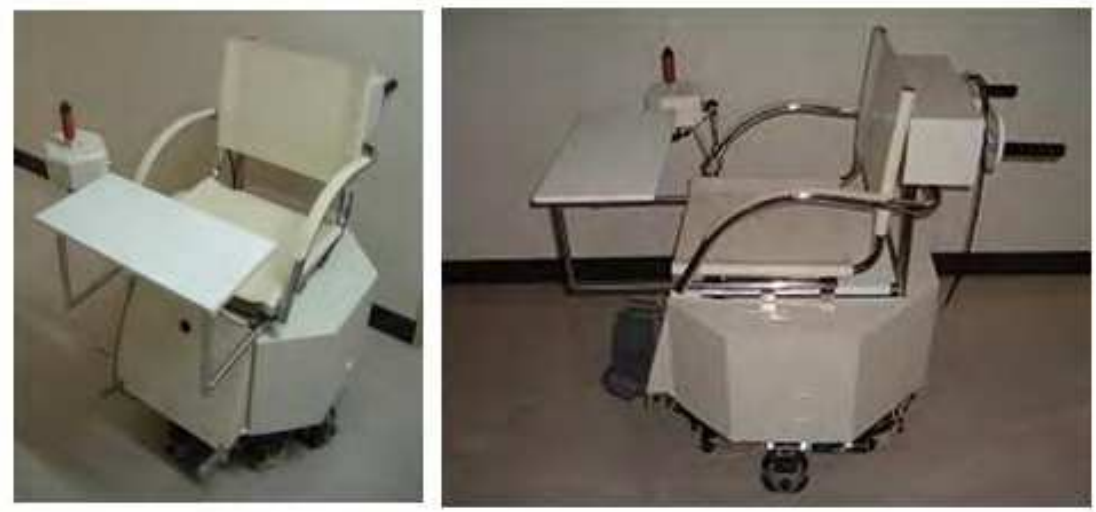

Fig. 5. Omni-directional wheelchair

Fig. 6(a) shows manufactured parts of omni-wheels. Omni-wheels are central to realize the arbitrary movement of the omni-directional mobile wheelchair (Urabano et al., 2005). As the assembly pictured in Fig. 6(b), the driving system consists of four omni-directional wheels, each of which connects to a motor. Notice that each wheel has passively driven free rollers at its circumference. The wheel that rolls perpendicularly to the direction of movement does not stop its movement because of the passively driven free rollers. These wheels thus facilitate the movement that is holonomic and omni-directional.
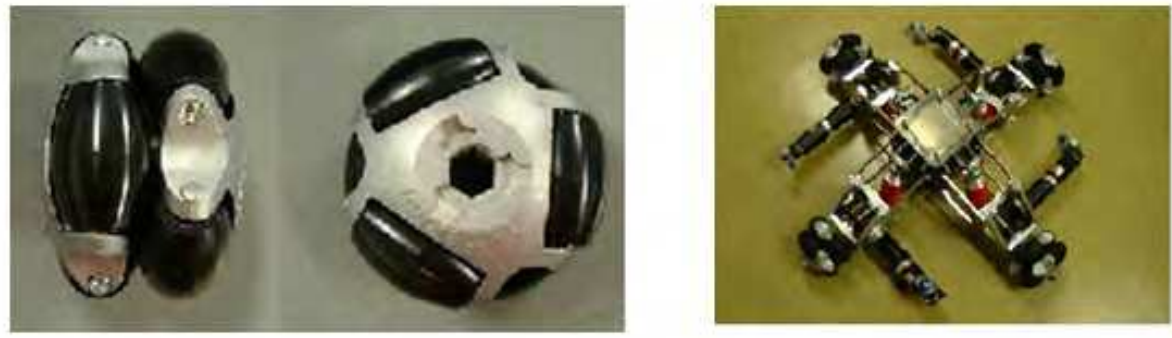

(a) Omni-wheel

(b) Arrangement of omni-wheels and their motors

Fig. 6. Components of omni-directional drive system 


\subsection{Position sensitive device and laser sensing technology}

An extension is made to find obstacles in the surrounding environment as well as to measure the distances to those objects. This can be done by the installation of range sensors, such as ultrasonic sensor, infrared sensor, and laser range scanner. In our first attempt, the ultrasonic sensors and the infrared sensors are attached to the omni-directional mobile wheelchair, as pictured in Fig. 7(a). This configuration, however, requires eight sensors in total to detect and measure the distance to the nearby obstacle as illustrated Fig. 7(b). In our second attempt, a laser range scanner is applied to reduce the number of sensors. The selected model, URG-X002 from Hokuyo Automatic Co., Ltd. (see Fig. 8(a)), is built as a high accuracy laser range scanner with a very compact design. It is not only the world's smallest range scanner of its class invented with advanced technology, but is highly reliable for the forefront use such as obstacle detection, environment recognition and path planning in robotics. The laser range sensor scans the surrounding environment by rotating the reflector (see Fig. 8(b)). The sensor has scanning speed of 100 [ms/scan], angle resolution of 0.36 [deg], measurement range of $270[\mathrm{deg}]$, and measurement distance of $0.02-4[\mathrm{~m}]$. This means that only two laser range sensors are required to measure the distance to the obstacles on the periphery of the omni-directional mobile wheelchair.

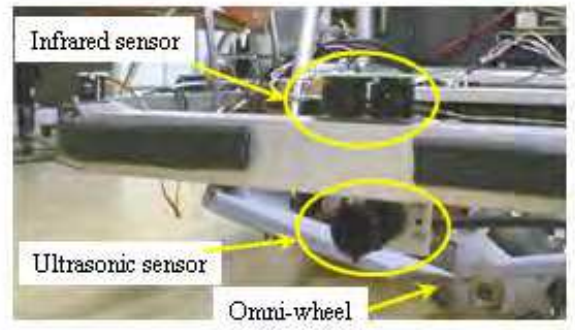

(a) Setting of ultrasonic sensors

Fig. 7. Installation of ultrasonic sensors

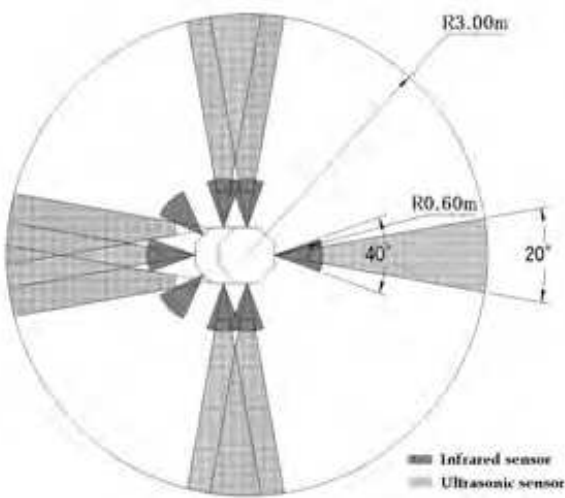

(b) Layout of sensors and measurement ranges

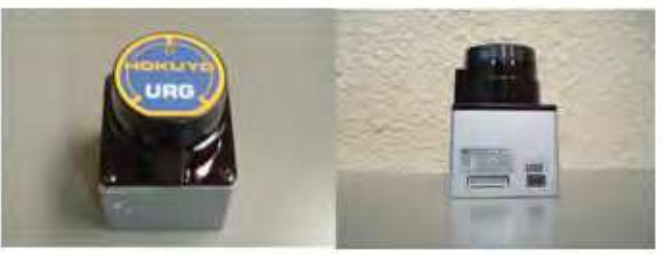

(a) External appearance

Fig. 8. Laser range scanner, URG-X002

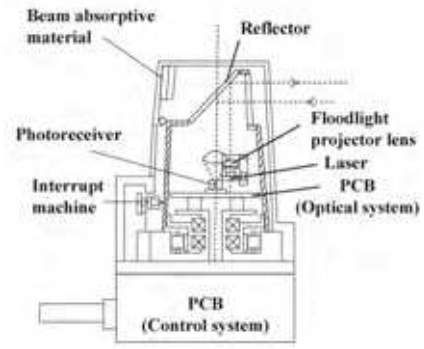

(b) Internal structure 
Fig. 9 shows the experimental performance of scanning environment by the use of the laser range scanners installed into the omni-directional mobile wheelchair. In this experiment, the omni-directional mobile wheelchair moves from point (a) to (f) as illustrated in the leftmost layout of Fig. 9. The developed system can successfully recognize obstacles and walls as the wheelchair proceeds to each point, and the map obtained at the point rotates at the same time the wheelchair changes its orientation.
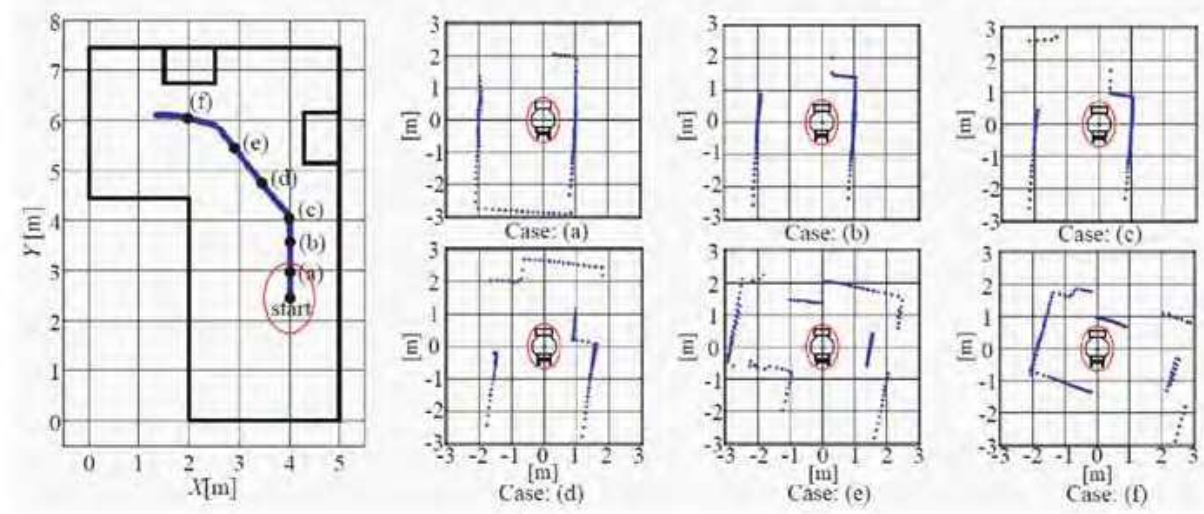

Fig. 9. Experimental results of recognizing environment

\subsection{Spatial mapping and automated tours}

Further extension is made to realize a semi-automated navigation system being combined with the obstacle detection capability described above. This is based on the real-time path planning of the tour to reach a goal point. The developed system is fully capable of avoiding the objects found in the path. Our approach uses potential field method (Arkin, 1987) constructed from a diffusion equation, in that the density of the target point is set 1 and the density of the region occupied by the obstacle is set 0 to establish boundary conditions. Given boundary conditions, the potential filed is generated from the iterative calculation of the discrete-diffusion equation. Accordingly, the wheelchair follows the path having an increasing order of densities to reach the target point. This is illustrated in Fig. 10 such that the target point holds density 1 and the area of obstacle holds density 0 as well as the potential field and trajectory of wheelchair's navigation path. 


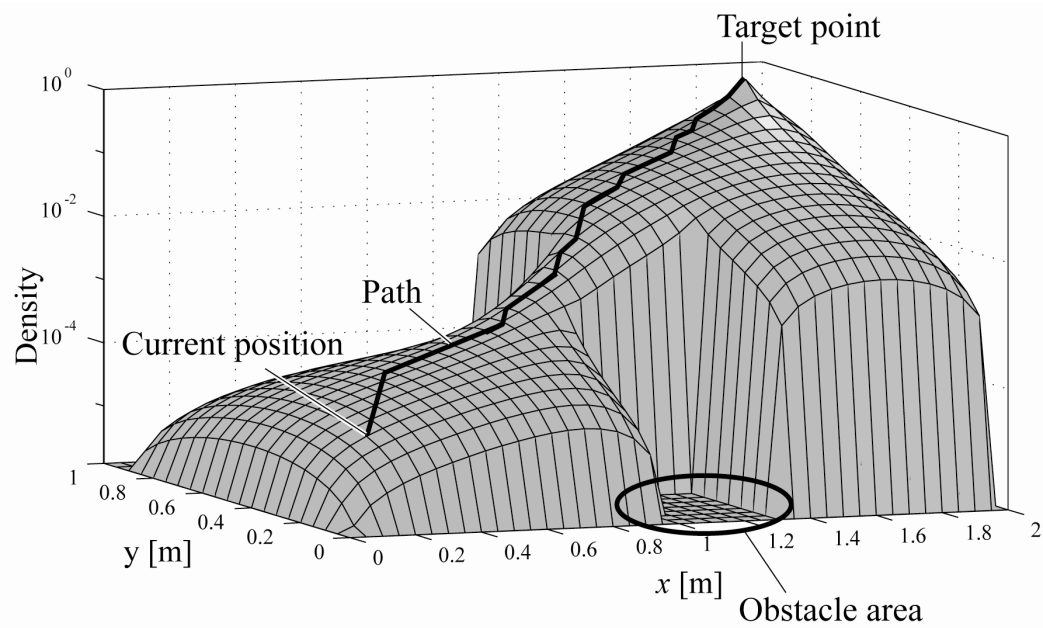

Fig. 10. Feature of potential field

\subsection{Haptic feedback joystick system}

The most recent extension made to omni-directional mobile wheelchair is a haptic feedback joystick system (Kondo et al., 2008). This is a control feedback system for which an alert is issued to the user by sending out a reaction force to the joystick when finding out obstacles in front. The system allows the user to navigate safely in narrow aisles, room entrances, and elevator rides. The signal to adjust the stiffness of joystick is determined based on the distance to the obstacle and the velocity of the wheelchair so that the maneuverability of joystick is to correspond to the drivability of wheelchair.

Another type of power-assisting system is built to help health-care attendants easily push and move heavyweight wheelchairs. Feedback control is similar to the haptic control mechanism. As shown in Fig. 11(a), a 6-axis force sensor is assembled into the supporting beam of the wheelchair's handles. The built system gives a boosting power to drive wheelchair, in which the magnitude of the power is computed by the reference velocity measured at the sensor from the attendant's force applied to the handles. The developed power-assisting system has shown effective support for wheelchair-cares.

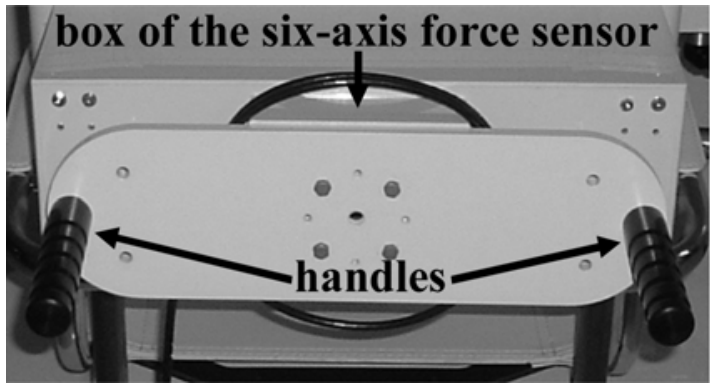

(a) Handles for applying force of attendant

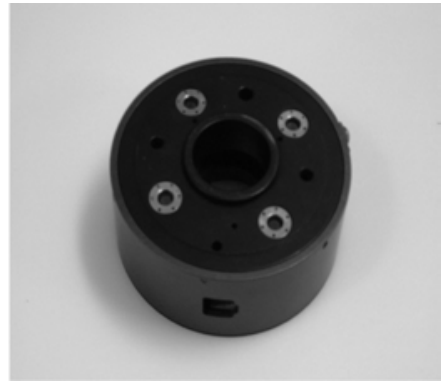

(b) 6-axis force sensor

Fig. 11. Handles with power assisting system for attendant 


\subsection{Bus Transit Services of Wheelchair Riders}

The New York City Transit in the Metropolitan Transportation Authority network operates the world's largest fleet of buses (4,373 public buses), serving over 666 million people per year for New York City to sustain its economy and attain projected job growth(MTA). These buses are equipped with wheelchair lifts either the front or back entrance of the vehicle, and have a "kneeling" feature that lowers the front entrance to within inches from the ground for easy access by any customer with mobility impairments or difficulty using the front steps. The Tokyo Metropolitan Bus Systems in Japan, by comparison, maintain the second largest scale of fleet, but do not run this level of services with lift-equipped vehicles (see Table 1 for the projected improvement from Japanese government standpoint).

\begin{tabular}{lrr}
\hline Transportation Media & 2003 & 2010 \\
\hline Railway cars & $24 \%$ & $30 \%$ \\
Non-step buses & $9 \%$ & $20-25 \%$ \\
Passenger ships & $4 \%$ & $50 \%$ \\
Airplanes & $32 \%$ & $40 \%$ \\
\hline
\end{tabular}

Table 1. Preset goals for the barrier-free implementations of Japanese public transportation (Ministry of Land. (2006))

The bus system is serving routes not served by the city subway system and outlying areas, and stopping every 2 blocks in almost 24 hours, The bus system is becoming a primary choice of transportation for wheelchair users living in the city. The city convention and visitors bureaus are offering guides that list wheelchair-accessible facilities. However, these brochures are rarely detailed enough to rely on and implement a full-scale mechatronics support for barrierfree accesses.

An on-line database system to facilitate the exchange of useful information among disabled bus riders and accessibility supporters in New York City is being built by our efforts. The system has a Web interface to find out the bus routing information on a trip from one point to another point in Manhattan. The capability beyond the "Trip Planner" web system (MTA Trip Planner System, 2009) implemented by the Metropolitan Transportation Authority is to respond using a map with appropriate paths (sequences of bus rides) to be taken to reach the destination along with the roadside information of toilet options, coffee shops and restaurants accommodating wheelchairs, quick repair services for motor trouble and battery replacement, and purchases of wheelchair equipments, etc., on the selected route. The system works with the GoogleMap viewing capability, thereby giving a quick way to narrow down the user choice of accessible sporting and cultural events.

The prototype system (see Fig. 12) currently stores all the traffic points (i.e., major stopping points and transfer points) of the MTA bus lines whose services are bound to Manhattan (thus the search capability is limited within Manhattan). A traffic point is a geographical location consisting of latitude and longitude, and all the points are structured as a directed graph in the database. A query transaction quickly computes acyclic paths between start location and destination. There can be multiple ways to travel by transferring to different bus lines. Thus, heuristics to avoid the explosive growth of traversal are devised for computing a maximal reachable set from a given point in the graph. 


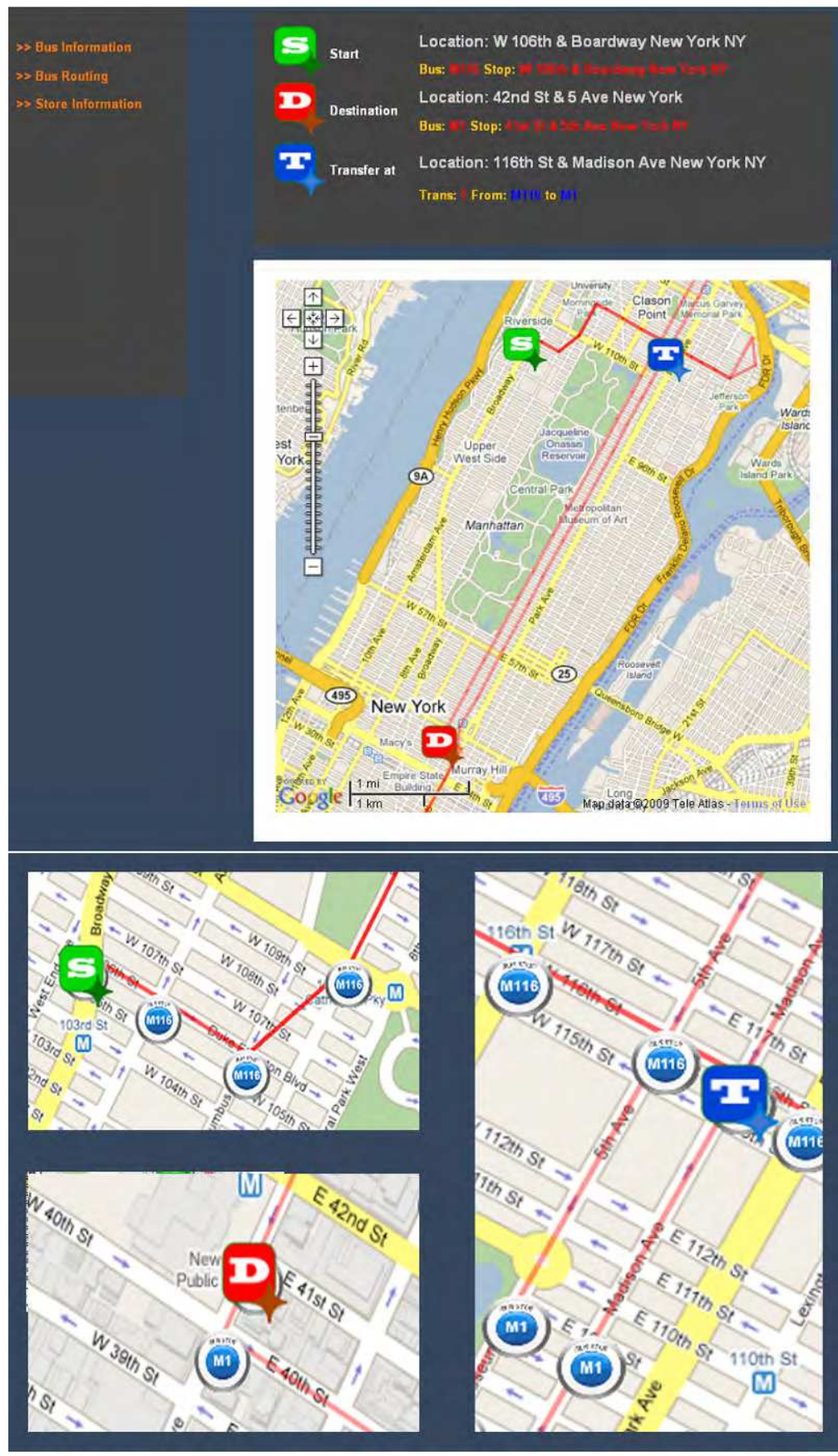

Fig. 12. Manhattan bus routing system 


\subsection{Community Support for Vulnerable People}

For those aging or disabled people whose condition makes them unable to walk, advanced mobile wheelchairs provide many benefits, such as maintaining mobility, continuing or broadening community and social activities, conserving strength and energy, and enhancing their general quality of life. Especially residents in metropolitan areas increasingly view the convenience of public transportation. They are becoming used to supply and retrieve information gathered for regional community. The accessibility improvement needs the exact same type of the cooperation of transportation companies and regional residents: transportation companies, private industries, public places, and any points of interest for residents such as restaurants, shopping centers, movie theaters, etc., must supply the accessibility information into a public database system, which in turn provides immediate retrieval for transportation and route selection (Kawaguchi and Chan, 2009).

The Web interface of our system has additional capability to accumulate community information in the form of a point of interest and/or assistive ability. The people in the metropolitan areas can register and augment categorized information in the database. Specifically, a person (e.g., restaurant owner) can contribute to the system by registering his/her item (e.g., restaurant) into a set of suitable categories (e.g., bathroom services, eatery, etc.). The registration is done by filling out the owner's identity (full name, contact address, phone, and email) as well as detailing the item to register and the category to classify. The information on the item includes name, address, phone, web URL, geo-position, capacity, up to 3 pictures, textual comment, and a link to the owner. The category can be chosen from those already in the database or newly created at the registration. There may be multiple categories to which the item needs to belong. For instance, restaurant can be in the categories of bathroom services and eatery.

The registration of the item is not immediately reflected to the database, but becomes pending at first. An administrator of the system needs to inspect if the requested registration is valid or not. Email is generated to the owner right after the administrator's decision. Category classification is not static. The administrator can reorganize it by merging and splitting branches. The registered items whose locations are close to the suggested course of travel are selectively shown to the GoogleMap result (see Fig. 13). 

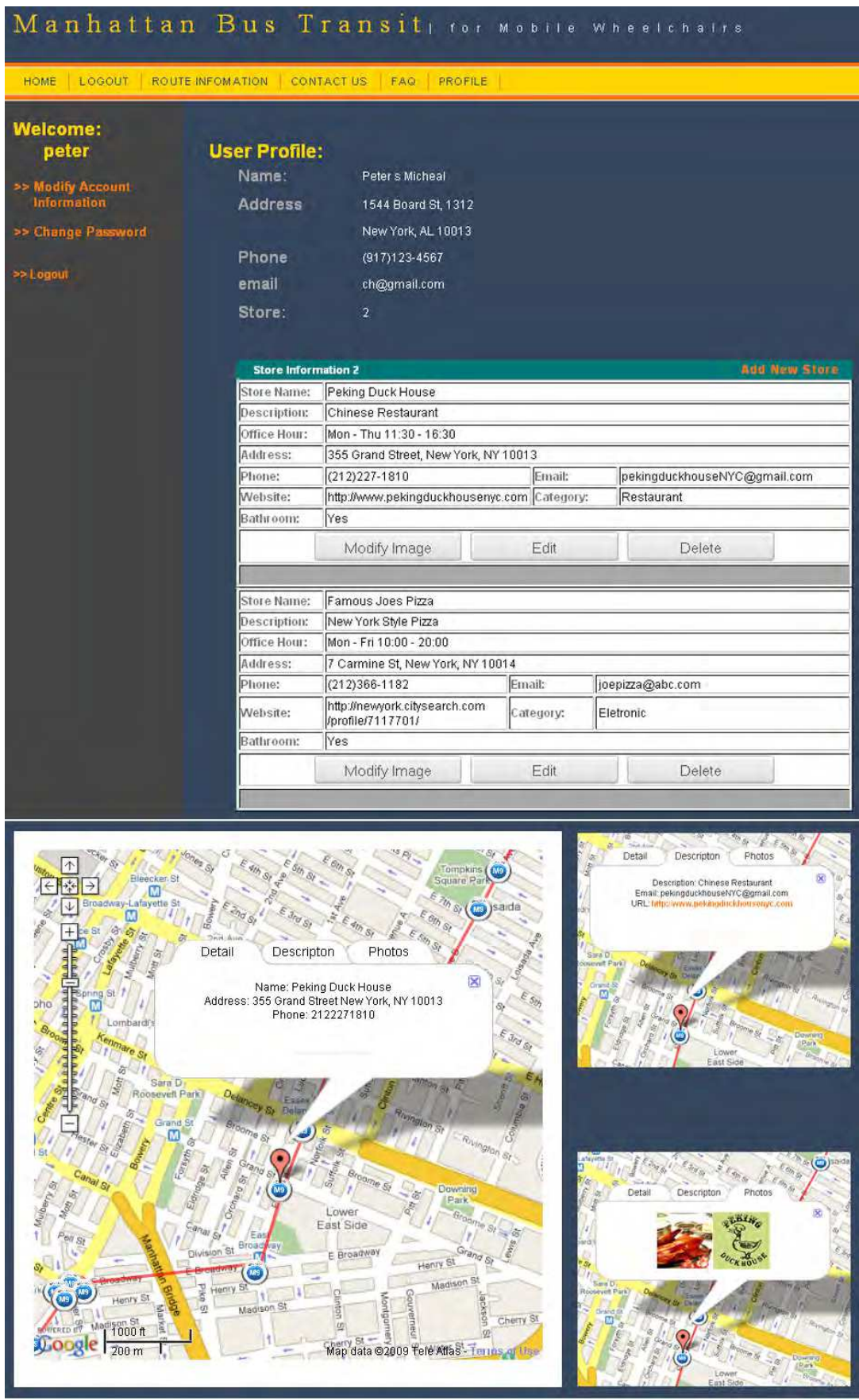

Fig. 13. Finding interest points with bus lines 


\section{Conclusions}

The subject of this chapter is a high-level discussion to address the problem of our society in the coming age. The mechatronics approach outlined here is the framework and methodology to cope with the influx of vulnerable people in mobile wheelchairs. The concept of the micro and macro-control architecture based on the proposed mechatronics approach is hoped to give the opportunity to understand and promote resulting benefits in broader developmental contexts. In the transportation aspect, mobility issue has powerful effects on the living conditions of those with physical disadvantage. The ultimate goal of our on-going, collaborative work is to make electric powered wheelchairs predict and avoid risky situations and navigate safely through the congested areas and confined spaces. Presently, we are gathering our studies into the envisioned mechatronics support. Additional mechanisms are also being explored, so that the onmi-directional movement as well as rider's posture-sensitive movement can be further improved to achieve more comfortable travel to arbitrary places. For those aging or disabled people whose condition makes them unable to walk, advanced mobile wheelchairs provide many benefits, such as maintaining mobility, continuing or broadening community and social activities, conserving strength and energy, and enhancing their general quality of life. To accomplish a more future oriented view of this class of services, today's information systems must be expanded to incorporate the community support and to objectively evaluate whether or not the public transportation services are in the perspectives of the user's needs. The mechatronics approach we proposed encompasses these views and shares the same sprit of the universal design.

\section{References}

Arkin, R. (1987). Motor schema based navigation for a mobile robot, The International Journal of Robotics Research, Vol.8, No.4, pp.92-112.

ADA. (1990). Americans with Disabilities Act of 1990 - ADA - 42 U.S. Code Chapter 126, U.S. Public Law 101-336, 104 Stat. 327, July 26, 1990.

CALL Centre. (1994). Learning through smart wheelchairs. Final report, Univ. of Edinburgh.

Chun-Ta Chen, Chieh-Chuan Feng and Yu-An Hsieh, (2004). Design and realization of a mobile wheelchair robot for all terrains. Advanced Robotics, Vol.17, No 8, December, pp. 739-760.

Cook, M.A. (2002). Assistive technologies: principles and practice. Mosby, $2^{\text {nd }}$ Edition.

International Labour Organization. (2007). Facts on disability in the world of work.

Jones, M. and Sanford, J. (1996). People with mobility impairments in the United States today and in 2010. Assistive Technology, 8.1, 43-53.

Kawaguchi, A., Noda, Y., Sato, Y., Kondo, Y., and Terashima, K. (2008). A mechatronics vision for smart wheelchairs, The 4th International Conference on Assistive Technologies (AT2008), pp. 145-150, Baltimore, Maryland, April 2008.

Kawaguchi, A and Chan, C. (2009). Community Support for Disabled Bus Riders: What Can We Do? International Conference of Computing in Engineering, Science and Informatics (ICC2009), Fullerton, California, April, 2009.

Kondo, Y., Miyoshi, T., Terashima, K., and Kitagawa, H. (2008). Navigation guidance control using haptic feedback for obstacle avoidance of omni-directional wheelchair. Proceedings of the 16th symposium on haptic interfaces for virtual environment and teleoperator systems, pp. 437-444, March 2008. 
Longmore, P.K. and Umansky, L. (2001). Editors, The New Disability History: American Perspectives, New York University Press.

Medical Equipment and Supplies Manufacturing Industry in the U.S. and its Foreign Trade (19972009), Industry report by Supplier Relations US, LLC, August 28, 2007.

Medical Supplies and Devices, Industry report by First Research, Inc., August 27, 2007.

Mechatronics principles, concepts and applications. Mahalik, Nitaigour Premchand, Tata McGrow-Hill, 2003.

Ministry of Land, Infrastructure and Transport. (2006). General Principles of Universal Design Policy.

MTA Guide to Accessible Transit, Brochure of New York City Metropolitan Transportation Authority, 2006.

MTA Trip Planner System. New York City Metropolitan Transportation Authority, accessible at http:/ / tripplanner.mta.info/ 2009.

Oe, Moriyuki. (2006). Problems and Implications of Japan's Aging Society for Future Urban Developments. Policy and Governance Working Paper Series No.89, March.

Orpwood, R. (1990) Design methodology for aids for the disabled. Journal of Medical Engineering \& Technology. Vol.14, No.1, pp. 2-10.

Pin, F. and Killough, S. (1994). A new family of omni-directional and holonomic wheeled platforms for mobile robots, IEEE Transactions on Robotics and Automation, Vol.10, No.4, pp.480-489.

Prassler, E., Scholz, J., and Fiorini, P. (2001). A robotics wheelchair for crowded public environment. IEEE Robotics \& Automation Magazine, Vol.8, No.1, pp. 38 - 45.

Power wheelchair market opportunities, strategies, and forecasts, 2007 to 2013, Market Research, April 2007.

Reinventing the wheelchair - autonomous robotic wheelchair projects in Europe improve mobility and safety. Issue of IEEE Robotics and Automation Magazine, 2001.

Removing Barriers: Planning meetings that are accessible to all participants, North Carolina Office on Disability and Health, 2005.

Richard C. Simpson, (2005) Smart Wheelchairs: A Literature Review J. Rehabilitation Res. $\mathcal{E}$ Dev. Vol.42, No.4, pp. 423-438.

Simon, R. M. (1997). Integrating Americans with disabilities act paratransit services and health and human services transportation. Transportation Research Board, April Number 10.

Simpson, R., LoPresti, E., Hayashi, S., Nourbakhsh, I., Miller, D. (2004) . The smart wheelchair component system. J. Rehabilitation Res. \& Dev. Vol.41 No.3B, pp. 429-442.

Simpson, C. R. (2005). Smart Wheelchairs: A Literature Review, J. Rehabilitation Res. \& Dev. Vol.42, No.4, pp. 423-438.

Urbano, J., Yang, Y., Terashima, K., Miyoshi, T., and Kitagawa, H. (2005). Navigation with comfort of omni-directional wheelchair driven by joystick. Proc. of the IFAC World Congress, Tu-M04-TP/14.

Wada, M. and Asada, M. (1999). Design and Control of a Variable Footprint Mechanism for Holonomic Omnidirectional Vehicles and its Application to Wheelchairs, IEEE Transactions on Robotics and Automation, Vol.15, No.6, pp.978-989.

World population ageing, United Nations, 2007.

Yanco, A. H. (1998). Wheelesley: A Robotic Wheelchair System: Indoor Navigation and User Interface. Lecture notes in computer science, Vol.1458, Springer Berlin. 


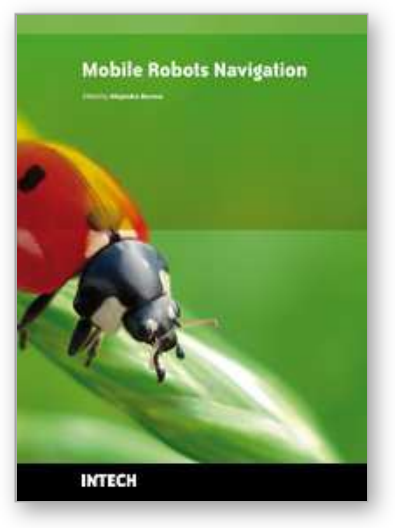

\author{
Mobile Robots Navigation \\ Edited by Alejandra Barrera
}

ISBN 978-953-307-076-6

Hard cover, 666 pages

Publisher InTech

Published online 01, March, 2010

Published in print edition March, 2010

Mobile robots navigation includes different interrelated activities: (i) perception, as obtaining and interpreting sensory information; (ii) exploration, as the strategy that guides the robot to select the next direction to go; (iii) mapping, involving the construction of a spatial representation by using the sensory information perceived; (iv) localization, as the strategy to estimate the robot position within the spatial map; (v) path planning, as the strategy to find a path towards a goal location being optimal or not; and (vi) path execution, where motor actions are determined and adapted to environmental changes. The book addresses those activities by integrating results from the research work of several authors all over the world. Research cases are documented in 32 chapters organized within 7 categories next described.

\title{
How to reference
}

In order to correctly reference this scholarly work, feel free to copy and paste the following:

Yoshiyuki Noda, Akira Kawaguchi and Kazuhiko Terashima (2010). A Mechatronics Vision for Smart Wheelchairs, Mobile Robots Navigation, Alejandra Barrera (Ed.), ISBN: 978-953-307-076-6, InTech, Available from: http://www.intechopen.com/books/mobile-robots-navigation/a-mechatronics-vision-for-smart-wheelchairs

\section{INTECH}

open science | open minds

\section{InTech Europe}

University Campus STeP Ri Slavka Krautzeka 83/A 51000 Rijeka, Croatia Phone: +385 (51) 770447 Fax: +385 (51) 686166 www.intechopen.com

\section{InTech China}

Unit 405, Office Block, Hotel Equatorial Shanghai No.65, Yan An Road (West), Shanghai, 200040, China 中国上海市延安西路65号上海国际贵都大饭店办公楼405单元 Phone: +86-21-62489820

Fax: $+86-21-62489821$ 
(C) 2010 The Author(s). Licensee IntechOpen. This chapter is distributed under the terms of the Creative Commons Attribution-NonCommercialShareAlike-3.0 License, which permits use, distribution and reproduction for non-commercial purposes, provided the original is properly cited and derivative works building on this content are distributed under the same license. 